\title{
Association study of C936T polymorphism of the $V E G F$ gene and the C242T polymorphism of the p22phox gene with diabetes mellitus type 2 and distal diabetic polyneuropathy
}

\author{
MELISSA MOTTIN GHISLENI, VANDERLEI BIOLCHI, BRUNA CRISTINA JORDON, \\ CLAUDETE REMPEL, JÚLIA PASQUALINI GENRO and ADRIANE POZZOBON \\ Department of Biological and Health Sciences, Postgraduate Program in Biotechnology, \\ Univates University Center, Rio Grande do Sul, Lajeado 95900-000, Brazil
}

Received October 19, 2014; Accepted June 5, 2015

DOI: $10.3892 / \mathrm{mmr} .2015 .3988$

\begin{abstract}
Even with long-term glycemic control, diabetes mellitus type 2 (DM2) remains the predominant cause of diabetic neuropathy. Single nucleotide polymorphism (SNP) C936T of the vascular endothelial growth factor (VEGF) gene and the SNP C242T of the p22phox (CYBA) gene have been investigated in relation to DM2 and its complications. The aim of the present study was to investigate the association between these two SNPs and DM2, and also between the SNPs and the signs and symptoms of diabetic distal polyneuropathy. The DM2 group consisted of 98 individuals and the control group consisted of 104 individuals. The results demonstrated that there was no association between the different genotypes or alleles and increased risk of the disease $(\mathrm{P}>0.05)$. With SNP C242T, a significant association with body mass index between the CTxTT genotypes $(\mathrm{P}=0.043)$ was identified; and the greatest body mass indexes were among individuals with the TT genotype. An association between the degree of neuropathic symptoms and genotypic/allelic distribution of these polymorphisms was not observed. In conclusion, the investigated polymorphisms are not correlated with the risk of developing DM2.
\end{abstract}

\section{Introduction}

The vascular endothelial growth factor gene (VEGF), located at chromosome $6 \mathrm{p} 21.3$, is involved in angiogenesis modulation under physiologic and pathologic conditions. It is involved in proliferation, differentiation, migration and survival of cells,

Correspondence to: Dr Vanderlei Biolchi, Department of Biological and Health Sciences, Postgraduate Program in Biotechnology, Univates University Center, Avelino Tallini 171, Rio Grande do Sul, Lajeado 95900-000, Brazil

E-mail: vbiolchi@gmail.com

Key words: single nucleotide polymorphism, diabetes, glycemic control, vascular endothelial growth factor, $p 22$ phox as well as nitric oxide production, release of other growth factors and sympathetic innervation. It also interacts with other angiogenic factors (1-3).

The enzymatic complex nicotinamide adenine dinucleotide phosphate (NADPH) oxidase has an important role in normal vascular function and in the development of vascular diseases, as it is the predominant source of reactive oxygen species (ROS) in the vascular system (4). Its subunit p22phox has drawn particular attention, due to the fundamental influence on its structure and activity $(5,6)$. The subunit $p 22$ phox gene, also termed $C Y B A$, is located on chromosome 16q24 $(7,8)$.

In total, $90-95 \%$ of diabetic patients have type 2 diabetes mellitus (DM2) (9). It is common that individuals are not diagnosed for several years due to the gradual development of hyperglycemia, which does not cause severe symptoms initially. Nevertheless, the patients are under an increased risk of developing macrovascular and microvascular complications triggered by endothelial dysfunction, a process in which an unbalance occurs during the generation of factors derived from the endothelium that are responsible for vascular tone control (10).

After diagnosis, even with long-term glycemic control, the disease remains the predominant cause of visual deficits, kidney disorders and lower-limb amputation (11). Diabetic neuropathy is considered one of the most common microvascular complications of diabetes, and distal polyneuropathy, is the most frequent form. It is progressive and irreversible, and one of the main causes of ulceration and amputation of the lower limbs (12). Its pathogenesis is still being investigated; however, it is currently hypothesized to be caused by neural phenotype alterations due to hyperglycemia, and vasa nervorum damage due to endothelial dysfunction $(13,14)$.

$V E G F$ has been recognized as the main mediator in the pathogenesis of cardiovascular complications of diabetes mellitus (15). Single nucleotide polymorphism (SNP) C936T (rs3025039) of the VEGF gene has been investigated in relation to cancer (16-19), endometriosis (20) and age-related macular degeneration (21). The effect of the SNP C242T (rs4673) of the p22phox gene on vascular function has also been extensively investigated, though the results were controversial (22-25). 
Given the influence of genetic predisposition on the development of diabetes and consequent angiopathies, the present study aimed to investigate the association between the C936T SNP of the VEGF gene and the C242T SNP of the p22phox gene with DM2, and also with the signs and symptoms of diabetic distal polyneuropathy.

\section{Materials and methods}

Study sample. The sample was composed of two groups, both consisting of individuals of Caucasian ethnicity, aged $>18$-years-old. One group was denominated 'DM2', consisted of individuals with type 2 diabetes mellitus, and the other one, denominated 'control,' consisted of individuals without diabetes mellitus. Patients were subjected to the following exclusion criteria: i) The lack of ability to understand or sign the informed consent form; ii) individuals with achondroplasia or cancer; and iii) pregnant females. Regarding the DM2 group, the following criteria were added to those mentioned above: iv) Individuals with a history or signs and symptoms of a central or peripheral nervous system disorder that may jeopardize the application of sensitivity tests; and v) individuals that had undergone lower-limb amputation. The study was approved by the local Ethics Committee of the Univates University Center (Rio Grande do Sul, Brazil). Informed consent was obtained from all participants.

Biochemical and molecule analyses. Blood $(7 \mathrm{ml})$ was collected from each individual; $4 \mathrm{ml}$ was used for DNA extraction and $3 \mathrm{ml}$ was used to determine the lipid profile. The participants were asked to fast for at least $12 \mathrm{~h}$ prior to blood collection, consuming only their usual medication and not practicing any physical activity or smoking in the $12 \mathrm{~h}$ leading up to blood collection (26).

Lipid profile evaluation. The levels of total cholesterol (TC), high density lipoprotein (HDL) and triglycerides (TG) of each individual were evaluated through the enzymatic colorimetric method, using commercial kits (Cholesterol Monoreagent K083, HDL Cholesterol Enzymatic K015, Triglycerides Monoreagent K117; BioClin/Quibasa, MG, Brazil), and the readings were taken using automated equipment, model BS120 (Mindray, Shenzhen, China). The evaluation of the low density lipoprotein (LDL) was performed using the Friedewald formula (LDL=TC-HDL-TG/5) when the triglyceride amount did not surpass $400 \mathrm{mg} / \mathrm{dl}$. The following reference levels were used: TC, desirable $\leq 200 \mathrm{mg} / \mathrm{dl}$ and high when >240 mg/dl; HDL, desirable when > $40 \mathrm{mg} / \mathrm{dl}$; LDL, desirable $\leq 140 \mathrm{mg} / \mathrm{dl}$, and high when $>160 \mathrm{mg} / \mathrm{dl}$; and TG, desirable $\leq 170 \mathrm{mg} / \mathrm{dl}$ and high when $>200 \mathrm{mg} / \mathrm{dl} \mathrm{(26)}$.

Identification of SNPs. The genomic DNA obtained from total peripheral blood was extracted using the salting out technique (27). The identification of polymorphisms was performed through polymerase chain reaction followed by enzymatic digestion by restriction enzyme. At first, in order to enlarge the fragments of the investigated genes, $V E G F$ and p22phox (CYBA), PCR reactions with the final volume of $50 \mu \mathrm{l}$ were performed. All the reagents used were obtained from Invitrogen Life Technologies (Carlsbad, CA, USA), whose applied concentrations for the two polymorphisms were: PCR buffer $(20 \mathrm{mM}$ buffer solution Tris- $\mathrm{HCl} \mathrm{pH} 8.4$ and $50 \mathrm{mM}$ $\mathrm{KCl}$ ), 1.25 units DNA Taq polymerase enzyme, $0.4 \mu \mathrm{M}$ sense and antisense primers, and $0.2 \mathrm{mM}$ dNTP mix. In the reactions for the $V E G F$ gene, the concentration of $\mathrm{MgCl}_{2}$ was $1.5 \mathrm{mM}$, and for the p22phox $(C Y B A)$ gene it was $2.0 \mathrm{mM}$.

The sequences of the applied primers for the investigation of polymorphism C936T of the VEGF gene were as follows: Forward: 5'-AAGGAAGAGGAGACTCTGCGCAGAGC-3' and reverse: 5'-TAAATGTATGTATGTGGGTGGGTG TGTCTAGAG-3' (GI:559098479 NM_001287044.1), and a fragment of 208 base pairs (bp) was generated. For the polymorphism $\mathrm{C} 242 \mathrm{~T}$ of the p22phox $(C Y B A)$ gene, the primers used were as follows: Forward: 5'-CCTTACAAATCCTGC ACACTAGA-3' and reverse: 5'-CTTTGGTGCTTGTGGGTA AAC-3' (GI:51473128 NT_010542.15), with the generation of a fragment of $428 \mathrm{bp}$. Table I shows the PCR reaction conditions.

Enzymatic digestion for verification of genotypes. After the PCR, the separation of the researched polymorphism fragments were attained using enzymatic digestion (with NlaIII and Afa I; Invitrogen Life Technologies). The protocols of the reactions are displayed in Table II. For the visualization of the fragments, electrophoresis was performed on $2 \%$ agarose gel (Sigma-Aldrich, St. Louis, MA, USA) stained with ethidium bromide, subjected to a 70 -volt current for $\sim 2 \mathrm{~h}$.

Evaluation of neuropathy symptoms. Forty participants from the DM2 group answered the Neuropathic Symptom Score questionnaire, which gathers answers related to symptoms associated to diabetic distal polyneuropathy (28).

Evaluation of signs of neuropathy. Sensitivity tests were applied on the same individuals that answered the Neuropathic Symptom Score questionnaire, in order to detect neuropathy signs. For testing deep sensibility, a calcaneus reflex test was performed with a Buck hammer (Prestige Medical, Northridge, CA, USA), impacted on the Achilles tendon bilaterally. The subject was placed in a standing position, with the knee of the tested leg flexed and supported on a chair, and the foot maintained in a pending position; reflexes were recorded as present or absent $(29,30)$.

Sensitivity to vibration was assessed by a stimulus generated using a $128 \mathrm{~Hz}$ tuning fork positioned over the tip and the dorsal surface of the hallux (distal phalanx) bilaterally, adding two points of stimulation on each foot. After stimulus demonstration provoked in the frontal surface of the forearm or back of the hand, the individual, maintained in a sitting position and with the tested foot supported on a stool, was asked to close their eyes and answer with the word 'yes' when he/she noticed the same sensation in the lower limbs (31).

Tactile sensitivity was verified in the same position as the previous test, through the application of the Semmes-Weinstein monofilament (AliMed, Inc., Dedham, MA, USA) corresponding to $10 \mathrm{~g}$ forces (orange color), on six points of the soles of the feet (metatarsal base and plantar pulp of the distal phalanx of the first, third and fifth toes), totaling 12 stimulated points. Likewise, initially the stimulus was demonstrated in the upper limb, for recognition purposes, and during the test, participants were asked to keep their eyes closed. The monofilament testing 
Table I. Programs used in PCR.

\begin{tabular}{|c|c|c|c|c|c|c|}
\hline \multirow[b]{2}{*}{ Step } & \multicolumn{3}{|c|}{$V E G F$} & \multicolumn{3}{|c|}{ p22phox $(C Y B A)$} \\
\hline & No. of cycles & Time & Temperature $\left({ }^{\circ} \mathrm{C}\right)$ & No. of cycles & Time & Temperature $\left({ }^{\circ} \mathrm{C}\right)$ \\
\hline \multirow[t]{2}{*}{ Denaturation } & 1 & $5 \mathrm{~min}$ & 94 & 1 & $2 \mathrm{~min}$ & 94 \\
\hline & 35 & $40 \mathrm{sec}$ & 94 & 37 & $1 \mathrm{~min}$ & 94 \\
\hline \multirow[t]{2}{*}{ Annealing } & 35 & $1 \mathrm{~min}$ & 64 & 37 & $50 \mathrm{sec}$ & 58 \\
\hline & 35 & $2 \min$ & 72 & 37 & $1 \mathrm{~min}$ & 72 \\
\hline Extension & 35 & $5 \mathrm{~min}$ & 72 & 37 & $5 \mathrm{~min}$ & 72 \\
\hline
\end{tabular}

PCR, polymerase chain reaction; $V E G F$, vascular endothelial growth factor.

Table II. Protocols for enzymatic digestion of polymorphisms C936T VEGF gene and C242T p22phox (CYBA) gene.

\begin{tabular}{lcc}
\hline & & Gene (SNP) \\
\cline { 2 - 3 } Variable & VEGF $(\mathrm{C} 936 \mathrm{~T})$ & $p 22 p h o x(C 242 T)$ \\
\hline Enzyme & Nla III-Invitrogen ${ }^{\circledR}$ & Afa I-Invitrogen $^{\circledR}$ \\
Incubation & $16 \mathrm{~h}$ & $8 \mathrm{~h}$ \\
Time & $37^{\circ} \mathrm{C}$ & $37^{\circ} \mathrm{C}$ \\
Temperature & & $428 \mathrm{pb}$ \\
Amplicon & $208 \mathrm{pb}$ & $428 \mathrm{pb}, 292 \mathrm{pb}, 166 \mathrm{pb}$ \\
CC genotype & $208 \mathrm{pb}, 122 \mathrm{pb}, 86 \mathrm{pb}$ & $292 \mathrm{pb}, 166 \mathrm{pb}$ \\
CT genotype & $122 \mathrm{pb}, 86 \mathrm{pb}$ & 16 \\
TT genotype & & \\
\hline
\end{tabular}

VEGF, vascular endothelial growth factor; SNP, single nucleotide polymorphism; pb, pairs of bases.

Table III. Characteristics of DM2 and control groups.

\begin{tabular}{|c|c|c|c|c|c|}
\hline Characteristic & $\mathrm{N}^{\mathrm{a}}$ & DM2 & $\mathrm{N}^{\mathrm{a}}$ & Control & P-value \\
\hline Female $^{\mathrm{b}}$ & $71(72.45 \%)$ & & $19(18.27 \%)$ & & \\
\hline Male $^{b}$ & $27(27.55 \%)$ & & $85(81.73 \%)$ & & \\
\hline $\operatorname{Age}^{c}$ (years) & 89 & $65(57-71)$ & 103 & $55(50-61)$ & $<0.001^{\mathrm{e}}$ \\
\hline $\mathrm{BMI}^{\mathrm{d}}\left(\mathrm{kg} / \mathrm{m}^{2}\right)$ & 86 & $31.56 \pm 5.64$ & 31 & $26.39 \pm 4.09$ & $<0.001^{\mathrm{f}}$ \\
\hline $\mathrm{TC}^{\mathrm{c}}(\mathrm{mg} / \mathrm{dl})$ & 90 & $165.00(150.00-186.75)$ & 74 & $190.50(170.25-230.00)$ & $<0.001^{\mathrm{e}}$ \\
\hline $\mathrm{TG}^{\mathrm{c}}(\mathrm{mg} / \mathrm{dl})$ & 90 & $128.50(96.75-185.00)$ & 74 & $125.00(84.50-180.25)$ & 0.351 \\
\hline $\mathrm{HDL}^{\mathrm{c}}(\mathrm{mg} / \mathrm{dl})$ & 90 & $46.00(39.00-54.00)$ & 74 & $49.00(40.00-60.00)$ & 0.074 \\
\hline $\mathrm{LDL}^{\mathrm{c}}(\mathrm{mg} / \mathrm{dl})$ & 87 & $92.40(73.20-109.20)$ & 72 & $114.40(96.95-143.20)$ & $<0.001^{\mathrm{e}}$ \\
\hline
\end{tabular}

${ }^{\mathrm{a}}$ Number of subjects studied in each variable; ${ }^{\mathrm{b}}$ values expressed as number of individuals (corresponding percentage in the group); ${ }^{\mathrm{c}}$ values expressed as median (percentiles 25/75); ${ }^{\mathrm{d}}$ values expressed as the mean \pm standard deviation; ${ }^{\mathrm{e}}$ non-parametric variables with significant differences after analysis through with the Mann-Whitney test; ${ }^{\mathrm{f}}$ parametric variable with a significant difference after analysis using Student's t-test. DM2, diabetes mellitus 2; BMI, body mass index; TC, total cholesterol; TG, triglycerides; HDL, high density lipoprotein; LDL, low-density lipoprotein.

pressure, characterized by its bending when perpendicularly applied to the skin surface, was performed randomly in the six described points, and there was no information to the individual concerning the location and the time of stimulation (32-34).
Anthropometric evaluation. The body mass index was determined (BMI=weight in $\mathrm{kg} /$ height in $\mathrm{m}^{2}$ ) and the parameters recommended by the World Health Organization (35) were used for diagnosis criteria purposes. 
Table IV. Genotypic and allelic distribution of the C936T SNP of the VEGF gene.

\begin{tabular}{|c|c|c|c|c|c|c|c|}
\hline$V E G F$ & $\mathrm{~N}^{\mathrm{a}}$ & $\mathrm{DM} 2$ & $\mathrm{~F}^{\mathrm{b}}$ & Control & $\mathrm{F}^{\mathrm{c}}$ & Group & P-value ${ }^{\mathrm{d}}$ \\
\hline \multicolumn{8}{|c|}{ Genotype } \\
\hline $\mathrm{CC}$ & 153 & 80 & 0.82 & 73 & 0.71 & $\mathrm{CCxCT}$ & 0.160 \\
\hline $\mathrm{CT}$ & 41 & 16 & 0.16 & 25 & 0.25 & СТхTT & 1.000 \\
\hline $\mathrm{TT}$ & 6 & 2 & 0.02 & 4 & 0.04 & CCxTT & 0.432 \\
\hline \multicolumn{8}{|l|}{ Alelle } \\
\hline $\mathrm{C}$ & 194 & 96 & 0.80 & 98 & 0.77 & $\mathrm{CC}+\mathrm{CT} \times \mathrm{TT}$ & 0.683 \\
\hline $\mathrm{T}$ & 47 & 18 & 0.20 & 29 & 0.23 & $\mathrm{CT}+\mathrm{TT} x \mathrm{CC}$ & 0.090 \\
\hline
\end{tabular}

${ }^{a}$ Total genotype samples/allele between the two groups; ${ }^{b}$ genotypic and allelic frequency references DM2 group; ${ }^{c}$ genotypic and allelic frequency concerning the control group; ${ }^{\mathrm{d}} \mathrm{P}$-values using the $\chi^{2}$ test followed by Fisher's exact test. SNP, single nucleotide polymorphism; VEGF, vascular endothelial growth factor.

Table V. Genotypic and allelic distribution of the C243T SNP of the p22phox (CYBA) gene.

\begin{tabular}{lrrrrrr}
\hline p22phox & $\mathrm{N}^{\mathrm{a}}$ & $\mathrm{DM} 2$ & $\mathrm{~F}^{\mathrm{b}}$ & Control & $\mathrm{F}^{\mathrm{c}}$ & Group $^{\text {P-value }}$ \\
\hline Genotype & & & & & & \\
CC & 100 & 52 & 0.55 & 48 & 0.56 & CCxCT \\
CT & 69 & 37 & 0.39 & 32 & 0.38 & CTxTT \\
TT & 10 & 5 & 0.05 & 5 & 0.06 & CCxTT \\
Alelle & 169 & 89 & 0.68 & 80 & 0.68 & CC+CTxTT \\
C & 79 & 42 & 0.32 & 37 & 0.32 & CT+TTxCC \\
T & & & & & 0.000 \\
\hline
\end{tabular}

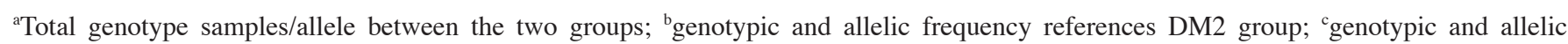
frequency concerning the control group; ${ }^{\mathrm{d} P}$-values using the $\chi^{2}$ test followed by Fisher's exact test. SNP, single nucleotide polymorphism.

Statistical analysis. Statistical analyses were conducted using the IBM SPSS software version 20 (IBM, Armonk, NY, USA). For the evaluation of the different groups investigated, parametric data were analyzed using Student's t-test and non-parametric data were analyzed using the Mann-Whitney test. The genotypic and allelic distribution was verified using a $\chi^{2}$ test, followed by Fisher's exact test and the Hardy-Weinberg equilibrium was also evaluated with the $\chi^{2}$ test. The risk of diabetes corrected to age was analyzed by binary logistic regression, as well as the analyses of associations between genotypic and allelic frequencies, lipid profile levels, sensitivity tests in the lower limbs and the degree of neuropathic symptoms. $\mathrm{P}<0.05$ was considered to indicate a statistically significant difference.

\section{Results}

Patient characteristics. The DM2 group consisted of 98 individuals, predominantly females, and the control group had 104 individuals, predominantly males. A significant difference between the groups was observed relating to age, BMI, TC and LDL levels $(\mathrm{P}<0.001)$, without any difference in relation to TG and HDL $(\mathrm{P}>0.05)$. The data concerning age, BMI and lipid profile of the groups are displayed in Table III.

\section{Genotypic and allelic distribution}

SNP C936T of the VEGF gene. SNP C936T genotyping was performed on 98 individuals from the DM2 group and 102 individuals from the control group (Table IV).

SNP C242T of the p22phox (CYBA) gene. SNP C242T genotyping was performed on 94 individuals from the DM2 group and 85 individuals of control group. Statistical analysis showed no difference between the groups, as observed in Table V.

DM2 risk corrected by age. The analysis by binary logistic regression corrected by age made it possible to verify whether genotypic or allelic frequencies of the polymorphisms investigated meant an increased risk of the occurrence of DM2. However, the results demonstrated that there was no association between the different genotypes or alleles and the increased risk of the disease $(\mathrm{P}>0.05)$.

Polymorphisms C963T and C242T and anthropometric and lipid profiles. In order to verify the association between the genotypic and allelic distribution of SNP C936T of the VEGF gene with BMI and lipid profile, these features were analyzed in a total of 109 people, belonging to the two groups (DM2 and control). Eighty-six of those were of the CC genotype, 21 of 
the CT genotype and two of the TT genotype. No associations were found between the C936T polymorphism and BMI or with the lipid profile of assessed subjects. The same analysis was performed separately for DM2 and control groups, and also showed no significant correlation $(\mathrm{P}>0.05)$.

For the SNP C242T of the p22phox (CYBA) gene, 104 participants were analyzed, and 56 of them were of the CC genotype, 41 the CT genotype and 7 the TT genotype. The analysis showed a significant association only regarding BMI between the CTxTT genotypes $(\mathrm{P}=0.043)$, and the greatest body mass indexes were among individuals with DM2, with the TT genotype. The mean BMI in the group with the CC genotype was $32.20( \pm 6.00) \mathrm{kg} / \mathrm{m}^{2}$, with CT genotype was $29.78( \pm 4.58) \mathrm{kg} / \mathrm{m}^{2}$ and TT genotype was $37.71( \pm 3.29) \mathrm{kg} / \mathrm{m} 2$.

C936T and C242T polymorphisms, and diabetic distal polyneuropathy signs. Concerning the C936T SNP of the VEGF gene, among the 40 individuals with DM2 that were evaluated, CC genotype was identified in 34 patients, the CT genotype in 5 and TT genotype in 1. In the diabetic group, the average of touch sensitive points was $7.40( \pm 4.85)$, points sensitive to vibration stimulus was $3.45( \pm 1.15)$, and points sensitive to the calcaneus reflex test was $1.10( \pm 0.95)$. The analysis did not show any association between the results of sensibility tests and genotypic and allelic distribution of the SNP C936T $(\mathrm{P}>0.05)$.

For the C242T SNP of the p22phox (CYBA) gene, of the same 40 individuals, 23 of them were of the CC genotype, 13 the CT genotype and 3 the TT genotype, and in 1 of the samples it was not possible to perform genotypic characterization. In the diabetic group, the average of touch sensitive points was $7.30( \pm 4.87)$, to points sensitive to vibration stimulus was $3.43( \pm 1.16)$, and points sensitive to the calcaneus reflex test was $1.07( \pm 0.95)$. Again, there was no significant difference between the results of the sensibility tests and genotypic and allelic distribution of SNP C242T ( $\mathrm{P}>0.05)$.

C936T and C242T polymorphisms and diabetic distal polyneuropathy symptoms. The diabetic distal polyneuropathy symptoms were classified as severe, moderate, mild and non-characteristic of neuropathy, according to the total number of points obtained in the Neuropathic Symptom Score, applied to the same 40 diabetic individuals that underwent the sensibility tests.

For SNP C936T of the VEGF gene, among the 11 individuals with severe symptoms, the CC genotype was identified in 9 individuals, and the $\mathrm{CT}$ in 2 . Among the 10 people with moderate symptoms, 9 individuals possessed the $\mathrm{CC}$ genotype and 2 the $\mathrm{CT}$. In the mild symptoms category, 7 individuals carried the CC genotype and 1 the TT genotype. In total, 11 individuals did not have a score matching neuropathic symptoms, 9 of them had a CC genotype and 2 had the CT genotype.

Concerning SNP C242T of the p22phox (CYBA) gene, of the 11 individuals presenting severe symptoms, 6 of them were of the CC genotype, 3 the CT genotype and 2 the TT genotype. Among 10 individuals with moderate symptoms, 6 of them exhibited the CC genotype, 3 the CT genotype and 1 the TT genotype. Among the 8 people with mild symptoms, 3 exhibited the CC gentoype, $4 \mathrm{CT}$ and $1 \mathrm{TT}$. Among the
11 people without typical neuropathy symptoms, 6 were of the CC genotype and 4 the CT genotype, so that in one sample the characterization was not possible.

After the statistical analysis, an association between the degree of neuropathic symptoms and genotypic and allelic distribution of investigated polymorphisms was not observed $(\mathrm{P}>0.05)$.

\section{Discussion}

The strong influence of ethnic differences on genetic predisposition of multifactorial diseases highlights the importance of regional studies that present a population profile and channel the focus of research into a greater understanding of the pathogenesis and improvement of prevention and treatment of these diseases.

Considering the influence of age in the development of DM2 $(9,36)$ analysis of the investigated polymorphisms was performed concerning the risk of the disease corrected by age. The results obtained were in accordance with such evidence, so the associations related to SNP C242T p22phox and C936T $V E G F$ indicated an increased risk of the development of DM2 over time, but without the influence of genotype.

Total cholesterol and LDL levels in the DM2 group were lower compared with the control group, and there was no significant difference between the groups concerning triglycerides and HDL levels.

Studies focused on the C936T SNP and distal polyneuropathy are scarce, compared with other diabetic complications. A study involving Korean individuals evaluated the role of this SNP in the development of microvascular pathologies in patients with DM2, and their results showed that the TT genotype was more frequent among diabetic patients with retinopathy, associated with higher plasma levels of VEGF (37). Conversely, other studies did not identify a significant association of the C936T SNP with diabetic retinopathy prevalence (38-41).

Studies focusing on the expression of VEGF and plasma levels in patients with diabetes with neuropathic complications exhibit conflicting findings (42-44). The precise role of VEGF in diabetic vascular complications remains to be fully elucidated. It is unknown whether the expression of the gene is, responsible for pathologic changes, in the case of retinopathy and peripheral arterial disease, or whether it represents a restorative response as a consequence of tissue and function changes (45). It is widely known that hypoxia is a major inducer of the transcription of the VEGF gene in several pathological conditions, but other factors also influence its expression, such as growth factors, inflammatory cytokines, hormones and oncogenic mutation events (46).

Even in the early stages of diabetic neuropathy, there is an occurrence of abnormalities in the vasa nervorum and loss of nerve fibers (47). Neural damage results typically in an increase of VEGF plasma levels in diabetic animals, with an increased expression in axons and dorsal ganglion (48). Therefore, ischemia and hypoxia in the nerves of patients with diabetes due to vasa nervorum microangiopathy has always been observed and may be a key pathogenic mechanism of diabetic neuropathy. Microvascular dysfunction observed in the peripheral nerve contributes to reducing endoneurial blood 
flow, leading to destruction of neural and Schwann cells and nerve degeneration (42).

Concerning the C242T SNP of the p22phox gene, studies emphasizing the correlation between this SNP and diabetic neuropathy are rare, when compared with research focused on other complications of the disease.

A study suggested that hyperglycemia may be a determinant in the vascular activation of NADPH oxidase, when it was demonstrated that the increased production of this enzyme is associated with abnormal vascular reactivity, with an increase in gene expression of the p22phox in the vessels of rodents with diabetes (49). Data generated by meta-analysis have shown an association between the T allele of SNP C242T and a higher risk of developing DM2 in Asian and non-Asian populations (50). However, other studies did not identify any association between the risk of the disease and this $\operatorname{SNP}(51,52)$.

An investigation into the impact of the variable C242T on high blood pressure and metabolic determinants of cardiovascular risk in a Brazilian population found no difference in genotypic distribution among hypertensive and normotensive individuals. Hypertensive individuals with the CC genotype showed lower fasting glucose, smaller abdominal circumference and lower diabetes mellitus prevalence. Among normotensive people, however, no significant differences were observed between the studied variables, which rendered it possible to conclude that the $\mathrm{T}$ allele can be used as a marker for adverse metabolic characteristics in hypertensive individuals (53).

It is hypothesized that, in DM2, the increased production of reactive oxygen species leads to the activation of the NADPH oxidase complex. The activation of this complex, along with others, leads to cellular apoptosis through low-density lipoprotein molecule oxidation due to oxidative stress (54). In this study, C242T did not present an association with the lipid profile values of the study population.

Certain studies have investigated the correlation of the C242T SNP with cardiovascular risk factors, obtaining conflicting results (55-57). A study involving a South Indian population found a lower frequency of the $\mathrm{T}$ allele among individuals with DM2 and coronary disease, compared with a diabetic group without any arterial impairment (58).

Drawing from the consulted studies, it is possible to confirm the complexity that exists between metabolic networks and the diverseness of characteristics when populations of different ethnic groups are compared. The mechanisms subsequent to the association of DM2 with vascular dysfunction are influenced by several aspects, such as cardiovascular risk factors and typical diabetic parameters (hyperglycemia, insulin resistance, obesity and inflammation) (59). Moreover, studies have demonstrated that diabetic complications can develop a while after events of hyperglycemia, through a phenomenon known as metabolic memory, triggered by persistent epigenetic changes (60).

In conclusion, according to the results of this study, the C936T polymorphism of the VEGF gene and C242T of the p22phox gene are not correlated with the risk of developing diabetes mellitus or neuropathic signs and symptoms. When considering the results of other studies, a substantial heterogeneity in the findings is observed, which demonstrates a complex link between the risk factors of DM, genetic predisposition and the development of angiopathic complications. Such complexity can be explained largely by the variability in ethnicity of the studied populations and by the influence of environmental factors on genetic expression. Further studies with a larger number of participants may help to elucidate the role of these polymorphisms in DM2 complications.

\section{Acknowledgements}

The authors would like to thank the Laboratory of Clinical Analysis (Univates) staff for their assistance with the analysis of the lipid profile. The translation of the article was performed using an English Language Service.

\section{References}

1. Andersen NF, Vogel U, Klausen TW, Gimsing P, Gregersen H, Abildgaard $\mathrm{N}$ and Vangsted AJ: Vascular endothelial growth factor (VEGF) gene polymorphisms may influence the efficacy of thalidomide in multiple myeloma. Int J Cancer 131: E636-E642, 2012.

2. Thanigaimani S, Kichenadasse G and Mangoni AA: The emerging role of vascular endothelial growth factor (VEGF) in vascular homeostasis: lessons from recent trials with anti-VEGF drugs. Curr Vasc Pharmacol 9: 358-380, 2011.

3. Ferrara $\mathrm{N}$ and Davis-Smyth T: The biology of vascular endothelial growth factor. Endocr Rev 18: 4-25, 1997.

4. Wang H, Albadawi H, Siddiquee Z, Stone JM, Panchenko MP, Watkins MT and Stone JR: Altered vascular activation due to deficiency of the NADPH oxidase component p22phox. Cardiovasc Pathol 23: 35-42, 2014.

5. Lepetsos P, Pampanos A, Lallos S, Kanavakis E, Korres D, Papavassiliou AG and Efstathopoulos N: Association of NADPH oxidase p22phox gene C242T, A640G and -930A/G polymorphisms with primary knee osteoarthritis in the Greek population. Mol Biol Rep 40: 5491-5499, 2013

6. Le NT, Corsetti JP, Dehoff-Sparks JL, Sparks CE, Fujiwara K and Abe J: Reactive oxygen species, SUMOylation and endothelial inflammation. Int J Inflam 2012: 678190, 2012.

7. Farrag W and Eid M: Association of the $\mathrm{C} 242 \mathrm{~T}$ polymorphism of the p22 phox gene with advanced carotid atherosclerosis in type 2 diabetes. Mol Med Rep 1: 679-684, 2008.

8. Dinauer MC, Pierce EA, Bruns GA, Curnutte JT and Orkin SH: Human neutrophil cytochrome b light chain (p22-phox). Gene structure, chromosomal location and mutations in cytochrome-negative autosomal recessive chronic granulomatous disease. J Clin Invest 86: 1729-1737, 1990.

9. American Diabetes Association: Diagnosis and classification of diabetes mellitus. Diabetes Care (35 Suppl 1): S64-S71, 2012.

10. Safiah Mokhtar S, M Vanhoutte P, WS Leung S, Imran Yusof M, Wan Sulaiman WA, Zaharil Mat Saad A, Suppian R and Ghulam Rasool AH: Reduced expression of prostacyclin synthase and nitric oxide synthase in subcutaneous arteries of type 2 diabetic patients. Tohoku J Exp Med 231: 217-222, 2013.

11. Girach A, Manner D and Porta M: Diabetic microvascular complications: Can patients at risk be identified? A review. Int J Clin Pract 60: 1471-1483, 2006.

12. Vinik AI and Mehrabyan A: Diabetic neuropathies. Med Clin North Am 88: 947-999, 2004.

13. Kovac B, Kovac B, Marusić-Emedi S, Svalina S and Demarin V: Clinical and electrophysiological signs of diabetic polyneuropathy-effect of glycemia and duration of diabetes mellitus. Acta Clin Croat 50: 149-157, 2011.

14. Hyer CF, Lee TH, Philbin TM and Berlet GC: Diabetic neuropathy: The painful foot. Foot Ankle Clin 9: 221-237, 2004.

15. Yang B, Cross DF, Ollerenshaw M, Millward BA and Demaine AG: Polymorphisms of the vascular endothelial growth factor and susceptibility to diabetic microvascular complications in patients with type 1 diabetes mellitus. J Diabetes Complications 17: 1-6, 2003.

16. Liu XL, Yang QF and Kong BH: Vascular endothelial growth factor $+936 \mathrm{C} / \mathrm{T}$ polymorphism and cancer risk in Asians: A meta-analysis. Genet Mol Res 12: 1924-1933, 2013. 
17. Mandal RK, Yadav SS, Panda AK and Khattri S: Vascular endothelial growth factor $936 \mathrm{c}>\mathrm{T}$ polymorphism increased oral cancer risk: Evidence from a meta-analysis. Genet Test Mol Biomarkers 17: 543-547, 2013.

18. Oliveira C, Lourenço GJ, Silva PM, Cardoso-Filho C, Favarelli $\mathrm{MH}$, Gonçales NS, Gurgel MS and Lima CS: Polymorphisms in the 5'- and 3'-untranslated region of the VEGF gene and sporadic breast cancer risk and clinicopathologic characteristics. Tumour Biol 32: 295-300, 2011.

19. Eroglu A, Gulec S and Akar N: Vascular endothelial growth factor C936T polymorphism in cancer patients with thrombosis. Am J Hematol 82: 174, 2007.

20. Xu S, Wu W, Sun H, Lu J, Yuan B, Xia Y, De Moor B, Marchal K, Wang $\mathrm{X}, \mathrm{Xu} \mathrm{P}$, et al: Association of the vascular endothelial growth factor gene polymorphisms $(-460 \mathrm{C} / \mathrm{T},+405 \mathrm{G} / \mathrm{C}$ and $+936 \mathrm{~T} / \mathrm{C}$ ) with endometriosis: A meta-analysis. Ann Hum Genet 76: 464-471, 2012.

21. Jiang Y, Liang G, Wang L, Jiang J, Du G and Huang Y: Association between vascular endothelial growth factor +936 $\mathrm{C} / \mathrm{T}$ gene polymorphism and age-related macular degeneration. J Int Med Res 41: 317-324, 2013.

22. Li BH, Zhang LL, Zhang BB, Yin YW, Dai LM, Pi Y, Guo L, Gao CY, Fang CQ, Wang JZ, et al: Association between NADPH oxidase p22(phox) C242T polymorphism and ischemic cerebrovascular disease: A meta-analysis. PLoS One 8: e56478, 2013.

23. De Oliveira Alvin R, Santos PC, Dias RG, Rodrigues MV, de Sa Cunha R, Mill JG, Junior WN, Krieger JE and Pereira AC: Association between the C242T polymorphism in the p22phox gene with arterial stiffness in the Brazilian population. Physiol Genomics 44: 587-592, 2012.

24. Schreiber R, Ferreira-Sae MC, Ronchi JA, Pio-Magalhães JA, Cipolli JA, Matos-Souza JR, Mill JG, Vercesi AE, Krieger JE, Franchini KG, et al: The C242T polymorphism of the p22-phox gene (CYBA) is associated with higher left ventricular mass in Brazilian hypertensive patients. BMC Med Genet 12: 114, 2011.

25. Schächinger V, Britten MB, Dimmeler S and Zeiher AM $\mathrm{NADH} / \mathrm{NADPH}$ oxidase $\mathrm{p} 22$ phox gene polymorphism is associated with improved coronary endothelial vasodilator function. Eur Heart J 22: 96-101, 2001.

26. Sposito AC, Caramelli B, Fonseca FA, Bertolami MC, Afiune Neto A, Souza AD, Lottenberg AM, Chacra AP, Faludi AA, Loures-Vale AA, et al: IV Brazilian guideline for dyslipidemia and atherosclerosis prevention: Department of atherosclerosis of brazilian society of cardiology. Arq Bras Cardiol (88 Suppl 1): $2-19,2007$

27. Lahiri DK and Nurnberger JI: A rapid non-enzymatic method for the preparation of HMW DNA from blood for RFLP studies Nucleic Acids Res 19: 5444, 1991

28. Young MJ, Boulton AJ, Macleod AF, Williams DR and Sonksen PH: A multicentre study of the prevalence of diabetic peripheral neuropathy in the United Kingdom hospital clinic population. Diabetologia 36: 150-154, 1993.

29. Al-Geffari M: Comparison of different screening tests for diagnosis of diabetic peripheral neuropathy in Primary Health Care setting. Int J Health Sci (Qassim) 6: 127-134, 2012.

30. Shehab DK, Al-Jarallah KF, Abraham M, Mojiminiyi OA, Al-Mohamedy $\mathrm{H}$ and Abdella NA: Back to basics: Ankle reflex in the evaluation of peripheral neuropathy in type 2 diabetes mellitus. QJM 105: 315-320, 2012.

31. Jayaprakash P, Bhansali A, Bhansali S, Dutta P, Anantharaman R, Shanmugasundar G and Ravikiran M: Validation of bedside methods in evaluation of diabetic peripheral neuropathy. Indian J Med Res 133: 645-649, 2011

32. Sumpio BE: Contemporary evaluation and management of the diabetic foot. Scientifica (Cairo) 2012: 435487, 2012

33. Feng Y, Schlösser FJ and Sumpio BE: The Semmes Weinstein monofilament examination is a significant predictor of the risk of foot ulceration and amputation in patients with diabetes mellitus. J Vasc Surg 53: 220-226, 2011

34. Perkins BA, Orszag A, Ngo M,Ng E, New P and Bril V: Prediction of incident diabetic neuropathy using the monofilament examination: A 4-year prospective study. Diabetes Care 33: 1549-1554, 2010.

35. No authors listed: Obesity: Preventing and managing the global epidemic. Report of a WHO consultation. World Health Organ Tech Rep Ser 894: 1-253, 2000.

36. Sicree R and Shaw J: Type 2 diabetes: An epidemic or not and why it is happening. Diabetol Metab Syndr 1: 75-81, 2007.
37. Kim HW, Ko GJ, Kang YS, Lee MH, Song HK, Kim HK and Cha DR: Role of the VEGF $936 \mathrm{C} / \mathrm{T}$ polymorphism in diabetic microvascular complications in type 2 diabetic patients. Nephrology (Carlton) 14: 681-688, 2009

38. Awata T, Inoue $\mathrm{K}$, Kurihara S, Ohkubo T, Watanabe M, Inukai K, Inoue I and Katayama S: A common polymorphism in the 5 -untranslated region of the VEGF gene is associated with diabetic retinopathy in type 2 diabetes. Diabetes 51: 1635-1639, 2002.

39. Yang X, Deng Y, Gu H, Lim A, Altankhuyag A, Jia W, Ma K, $\mathrm{Xu}$ J, Zou Y, Snellingen T, et al: Polymorphisms in the vascular endothelial growth factor gene and the risk of diabetic retinopathy in Chinese patients with type 2 diabetes. Mol Vis 17: 3088-3096, 2011.

40. Kangas-Kontio T, Vavuli S, Kakko SJ, Penna J, Savolainen ER, Savolainen MJ and Liinamaa MJ: Polymorphism of the manganese superoxide dismutase gene but not of vascular endothelial growth factor gene is a risk factor for diabetic retinopathy. Br J Ophthalmol 93: 1401-1406, 2009.

41. Uthra S, Raman R, Mukesh BN, Rajkumar SA, Padmaja KR, Paul PG, Lakshmipathy P, Gnanamoorthy P, Sharma T, McCarty CA, et al: Association of VEGF gene polymorphisms with diabetic retinopathy in a south Indian cohort. Ophthalmic Genet 29: 11-15, 2008.

42. Motawi TK, Rizk SM, Ibrahim IA and El-Emady YF: Alterations in circulating angiogenic and anti-angiogenic factors in type 2 diabetic patients with neuropathy. Cell Biochem Funct 32: 155-163, 2014.

43. Drela E, Stankowska K, Kulwas A and Rość D: Endothelial progenitor cells in diabetic foot syndrome. Adv Clin Exp 21: 249-254, 2012

44. Deguchi T, Hashiguchi T, Horinouchi S, Uto T, Oku H, Kimura K, Makisumi K and Arimura K: Serum VEGF increases in diabetic polyneuropathy, particularly in the neurologically active symptomatic stage. Diabet Med 26: 247-252, 2009

45. Bleda S, De Haro J, Varela C, Esparza L, Ferruelo A and Acin F: Vascular endothelial growth factor polymorphisms are involved in the late vascular complications in Type II diabetic patients. Diab Vasc Dis Res 9: 68-74, 2012.

46. Ferrara N: Vascular endothelial growth factor: Basic science and clinical progress. Endocr Rev 25: 581-611, 2004.

47. Costa PZ and Soares R: Neovascularization in diabetes and its complications. Unraveling the angiogenic paradox. Life Sci 92: 1037-1045, 2013

48. Wirostko B, Wong TY and Simó R: Vascular endothelial growth factor and diabetic complications. Prog Retin Eye Res 27: 608-621, 2008

49. Kim YK, Lee M, Son SM, Kim IJ, Lee WS, Rhim BY, Hong KW and Kim CD: Vascular NADH Oxidase is involved in impaired endothelium-dependent vasodilatation in OLETF rats, a model of type 2 diabetes. Diabetes 51: 522-527, 2002.

50. Sun Q, Yin Y, Zhu Z and Yan Z: Association of the C242T polymorphism in the NAD(P)H oxidase $\mathrm{P} 22$ phox gene with type 2 diabetes mellitus risk: A meta-analysis. Curr Med Res Opin 30: 415-422, 2014.

51. San José G, Fortuño A, Beloqui O, Díez J and Zalba G: NADPH oxidase CYBA polymorphisms, oxidative stress and cardiovascular diseases. Clin Sci (Lond) 114: 173-182, 2008.

52. Di Castelnuovo A, Soccio M, Iacoviello L, Evangelista V, Consoli A, Vanuzzo D, Diviacco S, Carluccio M, Rignanese L and De Caterina R: The C242T polymorphism of the $\mathrm{p} 22$ phox component of $\mathrm{NAD}(\mathrm{P}) \mathrm{H}$ oxidase and vascular risk. Two case-control studies and a meta-analysis. Thromb Haemost 99: 594-601, 2008

53. Schreiber R, Ferreira-Sae MC, Tucunduva AC, Mill JG, Costa FO, Krieger JE, Franchini KG, Pereira AC and Nadruz W Jr: CYBA C242T polymorphism is associated with obesity and diabetes mellitus in Brazilian hypertensive patients. Diabet Med 29: e55-e61, 2012.

54. Kassab A and Piwowar A: Cell oxidant stress delivery and cell dysfunction onset in type 2 diabetes. Biochimie 94: 1837-1848, 2012.

55. Schreiber R, Bellinazzi VR, Sposito AC, Mill JG, Krieger JE, Pereira AC and Nadruz W Jr: Influence of the C242T polymorphism of the p22-phox gene (CYBA) on the interaction between urinary sodium excretion and blood pressure in an urban Brazilian population. PLoS One 8: e81054, 2013.

56. Goliasch G, Wiesbauer F, Grafl A, Ponweiser E, Blessberger H, Tentzeris I, Wojta J, Schillinger M, Huber K, Maurer G, et al: The effect of p22-PHOX (CYBA) polymorphisms on premature coronary artery disease ( $\leq 40$ years of age). Thromb Haemost 105 : 529-534, 2011. 
57. Xaplanteris P, Vlachopoulos C, Baou K, Vassiliadou C, Dima I, Ioakeimidis $\mathrm{N}$ and Stefanadis $\mathrm{C}$ : The effect of p22(phox) $-930 \mathrm{~A} / \mathrm{G}, \mathrm{A} 640 \mathrm{G}$ and $\mathrm{C} 242 \mathrm{~T}$ polymorphisms of NADPH oxidase on peripheral and central pressures in healthy, normotensive individuals. Hypertens Res 33: 814-818, 2010.

58. Narne P, Ponnaluri KC, Singh S, Siraj M and Ishaq M: Relationship between NADPH oxidase p22phox C242T, PARP-1 Val762Ala polymorphisms, angiographically verified coronary artery disease and myocardial infarction in South Indian patients with type 2 diabetes mellitus. Thromb Res 130: e259-e265, 2012.
59. Naka KK, Papathanassiou K, Bechlioulis A, Kazakos N, Pappas K, Tigas S, Makriyiannis D, Tsatsoulis A and Michalis LK: Determinants of vascular function in patients with type 2 diabetes. Cardiovasc Diabetol 11: 127, 2012.

60. Pirola L, Balcerczyk A, Okabe J and El-Osta A: Epigenetic phenomena linked to diabetic complications. Nat Rev Endocrinol 6: 665-675, 2010. 